\title{
The significance of sodium in the preference for saccharin solutions'
}

ELLIOT S. VALENSTEIN

FELS RESEARCH INSTITUTE

To test a report that the sodium in the soluble form of saccharin played a significant metabolic role in maintaining saccharin preference, rats were given either tap water, saccharin or a Na-saccharin solution. When satiated, the consumption rate of $\mathrm{Na}$-saccharin was highest with no difference in water and saccharin consumption. During prolonged food deprivation water consumption was suppressed, but the consumption of both saccharin solutions remained significantly elevated. In a final satiation period the initial differences reappeared. Conclusion: A taste preference for $\mathrm{Na}$-saccharin, but during hunger, consumption of sodium free saccharin was persistently elevated.

In a recent report it was suggested that the persistence of the preference for saccharin solution may be related to the practice of using the soluble form of saccharin which contains sodium (Warren \& Warren, 1964). In that experiment, the preference for $\mathrm{Na}-\mathrm{sacch}$ arin persisted, but the initial preference of satiated mice for plain saccharin declined. The authors concluded that persistence of preference for Na-saccharin maybe related to the metabolic effects of increased sodium intake. Data from the present experiment do not support this conclusion.

Method

Fifteen male rats (290-300 gm) of the Holtzman albino strain were used. The Ss were divided into three groups of five each which were equivalent in average weight. Groups were also matched for water intake after recording their daily water consumption for one week. None of the animals had any experience with saccharin solutions prior to the experiment.

Animals were housed in individual cages and maintained on Purina Lab Chow. The food was available ad libitum during the "satiated" condition and available for $75 \mathrm{~min}$. each day during the "hungry" condition. The lights in the room were on for $12 \mathrm{hr}$. (7:00 AM - 7:00 $\mathrm{PM})$ and off for $12 \mathrm{hr}$. (7:00 PM - 7:00 AM).

The solutions were placed in $250 \mathrm{ml}$ graduates mounted on the front of the cages. Animals drank from standard metal drinking tubes. A plastic cylinder, attached to the floor of the cage under each drinking tube, collected any fluid that spilled. The amount of fluid actually consumed was measured at the same time every day by reading the graduates after the spillage had been replaced. The graduates were washed and refilled with fresh solutions every day.

Animals in the "water" group were provided with tap water and the other two groups were given in one case a saccharin (0-Benzoic Sulfimide) solution and in the other a Na-saccharin (Sodium-0-Benzoic Sulfimide) solution. A $.25 \%$ saccharin solution $(250 \mathrm{mg}$ per 100 $\mathrm{ml}$ of distilled water) was used. To compensate for the difference in molecular weight, a $.28 \% \mathrm{Na}-$ saccharin solution (277 mg per $100 \mathrm{ml}$ of distilled water) was used. Thus both saccharins were provided in a .014 molar solution. Each animal had the same solution available at all times.

Consumption of fluids was measured for all three groups during six satiated days, 36 days in the hunger condition and finally 18 days when again satiated. Results and Discussion

Figure 1 indicates that in the satiated condition animals do not drink any more of the saccharin solution than water, while the Na-saccharin is consumed at almost twice the rate of the other two fluids. These results are consistent with the data from several pilot studies undertaken in our laboratory. These preliminary studies revealed also that the difference in consumption rate between the two saccharin solutions persisted over an observational period lasting three weeks. Apparently, the animals had no difficulty distinguishing between the solutions and the differences in consumption were present on the first day. A test using several members of the laboratory staff as Ss revealed that no one had any difficulty in distinguishing between the two solutions, which were presented with an appropriate double blind procedure.

When the animals were deprived of food, the consumption of both saccharin solutions increased significantly while water decreased. The Na-saccharin curve reached an asymptote within the first six days of the hunger

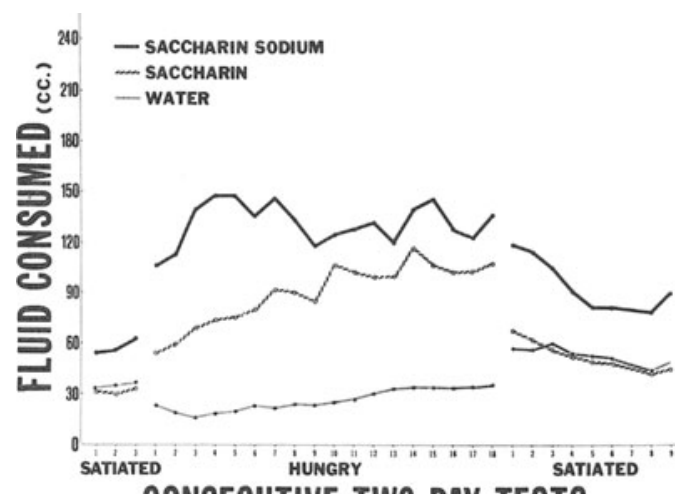

CONSECUTIVE TWO DAY TESTS

Fig. 1. A comparison of the average consumption of tap water, saccharın and Na-saccharin solutions ( $n=5$ in each group). 
period, but the saccharin consumption curve continued to increase for about 28 days.It is to be noted especially that even after 36 days the saccharin consumption curve exhibited no tendency to decrease. The immediate decrease in water consumption following food-deprivation was not unexpected as it is well-known that a considerable percentage of water intake is associated with eating ("prandial drinking"). Following the initial decrease in water intake the amount of water consumed gradually increased over the 36-day hunger period.

During the final 18 observation days animals were provided with food ad libitum. The consumption of the "plain" saccharin solution declined rapidly while water ingestion abmuptly increased so that by the fifth satiation day there was no difference in the intake of these two fluids. The Na-saccharin consumption declined more gradually to a level significantly above the saccharin and tap water curves. The fact that all three consumption curves were above the level observed during the initial satiation period probably reflects the growth of the animals during this period.
We would conclude that the greater consumption of the Na-saccharin solution is based on a taste preference. In our laboratory, with equal molar solutions, the $\mathrm{Na}-$ saccharin solution was always preferred over "plain" saccharin. Although the present experiment can not rule out the possibility that this taste preference is based upon some metabolic effects of sodium, this possibility seems rather remote in view of the immediacy of the preference. Particularly relevant are the present results which demonstrate that under fooddeprivation conditions animals will consume significantly more of a sodium free saccharin solution than water. This difference in consumption rate shows no tendency to decrease over time.

\section{Reference}

Warren, Roslyn P., \& Warren, R. M. Preference and nutritive value of "soluble" and "insoluble" saccharin solutions. Amer. Psychologist, $1964,19,496$.

\section{Note}

1. This research was supported by National Institutes of Health, Research Grant M-4529, and Career Development Award MH-4947. 